American Journal of Economics and Business Administration 3 (1): 95-100, 2011

ISSN 1945-5488

(C) 2010 Science Publications

\title{
Students’ Awareness and Requirements of Mobile Learning Services in the Higher Education Environment
}

\author{
Naji Shukri Alzaza and Abdul Razak Yaakub \\ Applied Science, College of Arts and Sciences, University Utara Malaysia, 06010 Sintok, Kedah
}

\begin{abstract}
Problem statement: M-learning is considered as the next generation of e-learning using mobile technologies. Students' awareness of such technology is one of the most focuses for success adoption. This study aims to investigate students' awareness and requirements of mobile learning services among Malaysian students in the higher education environment. Approach: The study found that the higher education environment now has the necessary mobile technology infrastructure to utilize m-learning. Results: Moreover, the results show that students have adequate knowledge and good awareness to use such technology in their education environment. Regarding the university mobile applications that students would like to use individually through mobile technologies, the exam result and course registration were the highest in rank, followed by calendar and schedule services. The highest limitations were the cost of transaction and slow data exchange with networks, followed by concerns over confidentiality of personal information. Conclusion: Future research should be conducted with a big number of respondents to ensure the representative and conclusive finding.
\end{abstract}

Key words: Mobile learning services, mobile technology, distance learning, e-learning, mobile commerce, General Packet Radio Service (GPRS), adequate knowledge, higher education environment

\section{INTRODUCTION}

In the recent years, mobile learning (m-learning) has moved from being a theory, academic exploration and technology idea, into a real and valuable contribution to learning environment and during the past decade every area of education has been affected by the introduction and use of such technology.

Mobile technology offers a new generation of learning for people of all ages anywhere and anytime.

Besides, m-learning provides many advantages including: Freedom to study with flexibility, low cost, timely application (Alzaza and Zulkifli, 2007), improvement experiential, authentic and reliable learning situations, enhanced availability of guidance, ease of use, support in learning situations (Seppala et al., 2002), fast production of digital learning materials and copyright issues, flexibility of learning (Sharples et al., 2002).

However, use of m-learning is growing rapidly in the higher education environments. The focus is on learning materials services and administrative services (Georgieva et al., 2005).

Regardless of the fact that e-learning has not reached the explosive growth figures which were commonly predicted in the mid-1990s, scholars and industry representatives are now turning their attention towards the m-learning (Feng et al., 2006) which could overcome the limitations of e-learning (Nasiri and Deng, 2009).

Mobile technologies: Mobile technologies potentially create a wide variety of uses and limitations that differ significantly from desktop and laptop technologies. It is the time to think of mobile phone devices as a new form of the handheld computer that has capabilities to be used in the learning processes (Prensky, 2005).

According to a survey conducted by the Malaysian Communications and Multimedia Commission (MCMC, 2008) in 2007, Malaysia today stands in the front of the ASEAN countries. The survey shows that, Internet users per 100 inhabitants in ASEAN countries, Malaysia (51.98\%) has the highest Internet users in 2007, while Singapore $43.62 \%$ and Brunei (43.35\%). Vietnam, Thailand, Indonesia and Filipina were 17.21, 13.0, 7.18 and $5.48 \%$ respectively and Laos, Cambodia, Myanmar were less than 1.0\%. Malaysia compared with some of economies countries; while United Kingdom (UK) was (56.03\%) and Malaysia was (51.98\%) while China was (10.35\%). 
Mobile penetration: Mobile penetrations increasingly affect the diffusion of information as well as business and learning activities. They gain broad acceptance due to the increased need in supporting the mobile workforce and the rapid improvement in the devices and wireless technologies for communication.

According to MCMC (2008), the mobile phones penetration in Association of Southeast Asian Nations (ASEAN) countries; Malaysia (72.3\%) stand in the front of the ASEAN after Singapore (109.3\%) followed by Brunei (66.5\%), Thailand (63.0\%) and Filipina (50.8\%). While Indonesia, Vietnam, Laos and Cambodia were 28.3, 18.2, 10.8 and 7.9\% respectively, Myanmar was only (0.4\%). Moreover, the survey indicates that the mobile penetration in the last four years kept growing in most states of Malaysia.

Moreover, MCMC survey investigated the use of internet through hand phones in Malaysia. It indicates that only $13.7 \%$ of users accessed the Internet through their hand phones. This is a drop of $4.7 \%$ points from year 2006. Among those who accessed the Internet on their mobiles, 84.4\% used General Packet Radio Service (GPRS) while 16.5\% used 3G, 12.1\% used WAP and 1.5\% used Enhanced Data Rates for Global Evolution (EDGE).

Mobile learning services in the higher education: M-learning is considered as the next form of e-learning using mobile technologies to enable teachers and learners to conduct their learning process anywhere and anytime. However, the main difference between elearning and m-learning is in the addition of capabilities and limitations in the evolution aspects. Scholars believe that m-learning is an e-learning regardless location and time.

Mirski and Abfalter (2004) defined m-learning as an emerging form of distance learning that offers both teachers and learners the opportunity to interact with educational material using a wireless handheld device. Georgieva et al. (2005) state that m-learning is based on the use of mobile devices supported with wireless technology.

Table 1 shows the main features of e-learning, wireless learning (w-learning) and m-learning. It shows that m-learning services are more portable than the previous kinds of services. The differentiation is based on the capability of the service which comprises the connection protocol used to access the service; the accessibility of the service regarding the place; the connectivity of the service based on the ability to connect via various networks and the size of the device and its screen which used in such service (Attewell, 2005; Wentzel et al., 2005).

Therefore, the m-learning services can be classified into two categories based on the information provided: (1) learning material services and (2) learning administrative services (Georgieva et al., 2005). Indeed, this study focuses on the administrative information.

Services of m-learning: Mobile learning services have been increased through the capability of the mobile technology itself. However, Georgieva et al. (2005) investigated the m-learning systems and classified them into seven divisions based on mobile devices and their capabilities: Communication technology used; communication between students and lecturers; access of services whether online or offline; the location of learners; information which comprise learning materials and administrative information and elearning standards whether supported or not (Rekkedal and Dye, 2007).

A survey conducted at Sofia University about the student's attitude towards the m-learning and its integration in education environment found that among students involved in Bachelor of Science (BSc) and Master of Science (MSc) programs at age (19-26) years old found that $62 \%$ appreciate the concept of mobile learning very much and just $10 \%$ of the respondents do not have idea at all (Yordanova, 2007).

Table 1: Comparison features of e-learning, w-learning and m-learning

\begin{tabular}{llll}
\hline Feature & E-learning & W-learning & M-Learning \\
\hline Protocol & Web-based & Web-Based & WAP-based \\
Accessibility & Anywhere & Campus & Anywhere and anytime \\
Network & Wired & Wireless & Wireless \\
Connectivity & Intranet or intranet networks & Local campus networks such as & Mobile networks: GSM, GPRS, UMTS or \\
& & Wi-Fi & CDMA \\
Device size & PC or laptop & Laptop or tablet PC & Mobile phone, smart phone or PDA phone \\
Screen size & "Normal” screen size, & "Medium” screen size, & very small (mobile phone) to a maximum of 480×640 \\
& $14-17$ inches & $10-15$ inches & pixels. More common for PDA is 240×320 pixels \\
\hline
\end{tabular}


According to Karim et al. (2006), mobile services in Malaysian educational environment concern on information delivery via SMS. The information consists of admission status, course registrations and examination results.

Corlett et al. (2005) provide a prototype application that enables students to access course material, view their timetables, communicate via email and instance messaging and organize their ideas and notes. They found course work tool has the most impact on the learning despite it has the lower perceived of usefulness.

Meng et al. (2004) provide a prototype that enables teachers and students to discuss with each other through PDAs or Personal Computers (PCs). Their prototype provides some beneficial services including shared whiteboard, online presentation and user management permissions. However, these services can make the communication between lecturers and their students easier.

Rekkedal and Dye (2007) investigated in depth a project for the Norwegian Knowledge Institute (NKI) that includes three intervals, which are From e-learning to m-learning (2000-2003), Mobile learning-the next generation of learning (2003-2005) and the ongoing project, incorporating mobile learning into mainstream education (2005-2007). The authors determined the specifications and characteristic of m-learning services that can provide via m-learning. The services are categorized based on the content of student course, ability to access the coursework functions, communication between learners and tutor using synchronous or asynchronous means, academic issues and rules and the navigation issues and capabilities.

Nevertheless, Barker et al. (2005) highlighted some considerations that need to be taken into account when exploring the adoption of m-learning range from limitations of the wireless technologies themselves, to broader issues such as safety and security and training.

Limitations of $\mathbf{m}$-learning: Limitations of m-learning services are considered as one of the issues that should be taken care of and be aware of when discussing mlearning implementation. Several studies (Corlett et al., 2005; Muthaiyah, 2004; Rekkedal and Dye, 2007; Seppala et al., 2002) noted that mobile devices have some limitations including: Memory size, battery life, high line cost and small screen. These limitations can hinder using mobile technology widely in learning. Nevertheless, Corlett et al. (2005) gave directions to extend the wireless network across the campus and to redesign software as well as hardware for m-learning purposes. Hence, university environment will be adequate to utilize the latest technology innovation without delay (Seppala et al., 2002).

However, developments in telecommunication technology provide new facilities and interfaces for students and staff of universities. In order to improve the organizational infrastructure for students and staff, every new technology arriving to the market has to be investigated for its benefit for daily use. In the case of the WAP, the consortium of Mobile Services for Campus and Student needs "Campus Mobil" was founded in order to investigate innovative services based on this technology (Barker et al., 2005).

\section{MATERIALS AND METHODS}

This preliminary study aims to explore the students' awareness and requirements of mobile learning services among Malaysian students in the higher education environment. The instrument was adapted from Kim et al. (2006) and Walton et al. (2005). The survey was piloted and some minor changes were made. The instrument comprises two parts: Student's awareness of mobile learning services aspects and general information. The first part covers six dimensions that include the following: Awareness of mobile learning service aspects, current access to learning resources, mobile technologies for learning services, applications used through mobile technologies, limitations of mobile technologies and the university mobile services that suggested to using through mobile technologies. A 5-point Likert scale anchored by "Strongly Disagree" (1) and Strongly Agree (5) was used. The General Information part functions as a mechanism to collect users' demographic data and users' experience and knowledge with the mobile technology media.

\section{RESULTS AND DISCUSSION}

A sample of 261 random selected students responding. $36.4 \%$ of respondents were male and $63.6 \%$ female, $85.8 \%$ were under the age of 26 . Despite science and business made up the largest groups of respondents 46.4 and $44.4 \%$, respectively, art studies were only $9.2 \%$. In terms of education level, Bachelor made up the largest number with $86.2 \%$, followed by master degree with $11.9 \%$ and each of Ph.D. and diploma was $1.9 \%$. This indicates that the findings represent opinions of different levels of students.

A 95\% of the participants declared that they own a mobile device. Among those who own mobile devices, $80.1 \%$ own mobile phone and $10 \%$ own smart phone, while only $5 \%$ own PDA. In terms of mobile 
application experience $51.7 \%$ have less than 5 years of using the mobile application experience; $42.5 \%$ have experience between 5 and 9 years; while only 5.7 have more than or equal 10 years. This indicates that the respondent experience, in terms of mobile application, is respectable.

This study also examined the data on how participants connect through the wireless networks, 44.1\% of participants are connecting through GPRS and $37.2 \%$ connecting through $\mathrm{Wi}-\mathrm{Fi}$, while $18.8 \%$ have no knowledge or experience before about the terms of wireless network connection. Regarding the mobile service provider, MAXIS (44.8\%) made up the highest rate followed by CELCOM (34.5\%) and DIGI (20.7\%).

For the ranges of five point Likert-scales were categorized into equal sized categories of low, moderate and high. Therefore, scores of less than 2.33 [4/3 + lowest value (1)] is considered as low; scores of 3.67 [highest value (5)-4/3] is considered high and those in between considered moderate. Consequently, this study explored the students' awareness of the various mobile technology names. The abbreviations used below are NA = Not Aware, $\mathrm{SA}=$ Somewhat Aware, NS = Not Sure, $\mathrm{A}=$ Aware, $\mathrm{VA}=$ Very Aware. Figure 1 shows that the participants are highly aware in terms of Laptop/Notebook (34.5\% A, 57.5\% VA) and Wireless connection such as Wi-Fi and GPRS. The remained were in moderate of awareness. However, for all mobile technology names, more than 50 percent of participants were aware or very aware of such technology.

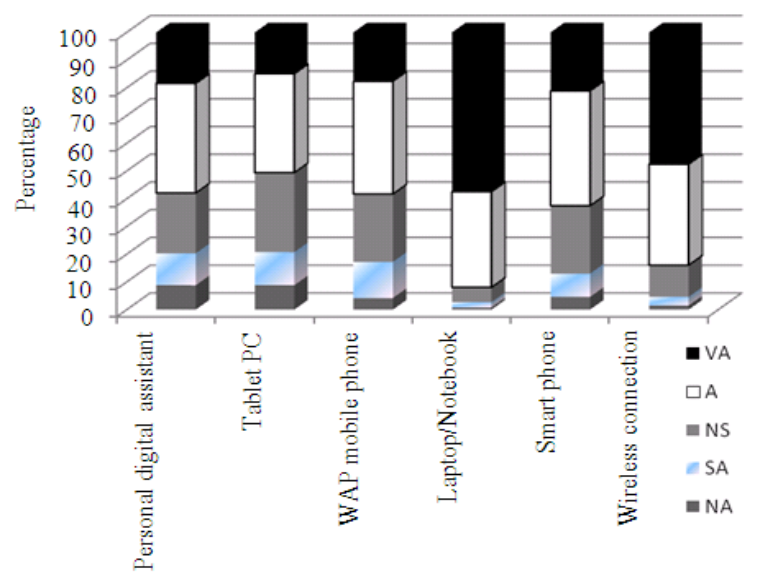

Fig. 1: Students' awareness of mobile technologies names
The abbreviations used below are SD = Strongly Disagree, $\mathrm{D}=$ Disagree, $\mathrm{N}=$ Neutral, $\mathrm{A}=$ Agree, $\mathrm{SA}=$ Strongly Agree. Study found that there was a correlation with the participant and learning resources where it found that they were highly agreed that the distance access to the University learning resources (47.1 A, 24.9\% SA) with 82 percent overall agree and the access to learning resources while placement (47.1 A, 22.2\% SA) are important for their learning. Furthermore, the results indicate that the students' perceptions of various barriers and obstacles they face when accessing online learning resources, were moderate. While the mean of difficulty in accessing electronically the University learning resources from workplace was 2.89 followed by difficulty in visiting the University learning resources (2.76), the mean of poor of awareness how to use was 2.59 followed by 2.48 for "do not have access to a University academic service by distance means”.

The potential for mobile technologies was examined for learning services. Participants were highly forwarded to be informed up-to-date anytime and regardless the place. Table 2 Shows that the most beneficial aspects of using mobile technologies for learning services were to give students an immediate access to information (51.3\% A, 29.1\% SA) and give them current information (54.8 A, 27.6\% SA). Moreover, they were highly forwarded to keep in touch with their classmates and their lecturers, as well. The results also show that the increase contact with other students $(\mathrm{M}=3.97)$ followed by provide increased contact with place of study ( $\mathrm{M}=3.91)$ were highly mean followed by improve the ability to study $(\mathrm{M}=3.87)$ and Increase contact with lecturers $(\mathrm{M}=3.84)$.

Participants were also asked about the mobile applications that they like to use through mobile technologies. The uses for normal mobile phone (calling, SMS and MMS) were the high rank (33.3\% A, $59.4 \%$ SA), followed by internet access (35.2\% A, $49.8 \%$ SA). Furthermore, the usage for Intranet access (Local network), Word processing, Calendar and Database access were highly usage.

The perceived limitations of mobile technologies were also investigated. The cost of transaction (40.6\% A, 26.1\% SA) and slow data exchange with networks were the highest ranked limitation (39.8\% A, 24.9\% SA), followed by concerns over confidentiality of personal information (47.1\% A, 18.8\% SA). Usability of mobile's keyboard was in low ranking, followed by need for training to use the device and poor portability of laptop.

Regarding the University mobile applications that participants would like to use individually through mobile technologies, as shown in Table 3, the exam result (36.8\% A, 44.8\% SA) and course registration 
Am. J. of Economics and Business Administration 3 (1): 95-100, 2011

Table 2: Students' views on the use of mobile technologies for learning services

\begin{tabular}{|c|c|c|c|c|c|c|}
\hline \multirow[b]{2}{*}{ Item } & \multicolumn{6}{|c|}{ Percent } \\
\hline & SD & $\mathrm{D}$ & $\mathrm{N}$ & A & SA & $\mathrm{M}$ \\
\hline Give me current information & 0.4 & 4.2 & 13.0 & 54.8 & 27.6 & 4.50 \\
\hline Provide me with increased contact with my place of study & 0.4 & 5.0 & 19.9 & 52.5 & 22.2 & 3.91 \\
\hline Increase my contact with other students & 0.4 & 3.4 & 18.4 & 54.8 & 23.0 & 3.97 \\
\hline Increase my contact with my lecturers & 0.4 & 7.7 & 19.9 & 51.3 & 20.7 & 3.84 \\
\hline Give me immediate access to information & 0.8 & 2.7 & 16.1 & 51.3 & 29.1 & 4.05 \\
\hline Improve my ability to study & 1.5 & 3.1 & 26.8 & 44.4 & 24.1 & 3.87 \\
\hline
\end{tabular}

Table 3: The important university mobile services

\begin{tabular}{|c|c|c|c|c|c|c|}
\hline \multirow[b]{2}{*}{ Services } & \multicolumn{6}{|c|}{ Percentage } \\
\hline & SD & $\mathrm{D}$ & $\mathrm{N}$ & A & SA & $\mathrm{M}$ \\
\hline Library services & 1.1 & 5.7 & 23.0 & 39.5 & 30.7 & 3.93 \\
\hline Course registration & 1.1 & 6.5 & 15.3 & 45.6 & 31.4 & 4.00 \\
\hline Calendar, timetable, or schedule services & 0.8 & 5.4 & 21.1 & 42.9 & 29.9 & 3.96 \\
\hline Exam result & 1.1 & 2.7 & 14.9 & 36.8 & 44.4 & 4.21 \\
\hline Admission status & 1.1 & 6.5 & 22.2 & 41.0 & 29.1 & 3.90 \\
\hline Treasury & 1.9 & 6.1 & 22.6 & 39.1 & 30.3 & 3.90 \\
\hline Campus facilities & 1.9 & 6.1 & 25.7 & 42.1 & 24.1 & 3.80 \\
\hline International students' services & 3.4 & 12.3 & 30.7 & 30.3 & 23.4 & 3.58 \\
\hline Alert system & 2.7 & 8.8 & 23.8 & 35.2 & 29.5 & 3.80 \\
\hline
\end{tabular}

(45.6\% A, 31.4\% SA) were the highest rank, followed by Calendar and Schedule services (42.9\% A, 29.9\% SA), Library services (39.5\% A, 30.7\% SA), Treasury (39.1\% A, 30.3\% SA), Admission status $(41.0 \% \mathrm{~A}$, 29.1\% SA), Campus Facilities (42.1\% A, 24.1\% SA) and Alert system (35.2\% A, 29.5\% SA). The international students' services (30.3\% A, 23.4\% SA) was the in the last rank.

\section{CONCLUSION}

Nowadays, m-learning services are interesting and very recent addition as a new vital platform for the higher education environment. This study explored the requirement for utilizing m-learning services in the higher education environment. Moreover, it provided the knowledge base about the current state of students' awareness about m-learning services. Both of the environment and the infrastructure are appropriate to diffuse m-learning in the higher education environment.

The results indicate that the higher education environment has the required infrastructure to utilize m-learning services. Furthermore, the results show that the students have adequate knowledge and awareness to use such technology in their education environment. However, the barriers and obstacles that could be faced during the actual use of mobile learning should be considered. Literature shows that while the limitations of mobile technology are reducing over time, the capabilities are going on increasingly. This study shows that the limitations of m-learning for education are well concerned by students.

However, Mobile wirelesses technology use in higher education will keep growing and will become the choice of the learning environment.

This study is part of research to investigate adoption and diffusion of m-learning services among students in the higher education environment.

\section{REFERENCES}

Alzaza, N.S. and A.N. Zulkifli, 2007. Mobile Based Library Loan Service (MBLLS). Proceeding of the Rural ICT Development Conference, Nov. 20-21, Executive Development Centre (EDC), Sintok, Malaysia, $\quad$ pp: 1-8. http://najishukri.files.wordpress.com/2010/05/pape rmblls.pdf

Attewell, J., 2005. Mobile Technologies and Learning: A Technology Update and m-Learning Project Summary. 1st Edn., The Learning and Skills Development Agency, London, pp: 19.

Barker, A., G. Krull and B. Mallinson, 2005. A Proposed Theoretical Model for M-Learning Adoption in Developing Countries. Proceeding of the Mobile technology: The future of learning in your hands, Oct. 25-28. Cape Town, South Africa, pp: 1-10.

Corlett, D., M. Sharples, T. Chan and S. Bull, 2005. A mobile learning organiser for university students. J. Comput. Assisted Learn., 21: 162-169. DOI: 10.1111/j.1365-2729.2005.00124.x 
Feng, H., T. Hoegler and W. Stucky, 2006. Exploring the critical success factors for mobile commerce. Proceding of the International Conference on Mobile Business, June, 26-27, IEEE Xplore Press, Copenhagen, Denmark, pp: 40-40. DOI: 10.1109/ICMB.2006.15

Georgieva, E., A. Smrikarov and T. Georgiev, 2005. A general classification of mobile learning systems. Proceeding of the International Conference on Computer Systems and TechnologiesCompSysTech 2005, June 17-18, Technical University, Varna, Bulgaria, pp: 11-16.

Karim, N.S.A., S.H. Darus and R. Hussin, 2006. Mobile phone applications in academic library services: A students' feedback survey. CampusWide Inform. Sys., 23: 35-51. DOI: 10.1108/10650740610639723

Kim, S.H., C. Mims and K.P. Holmes, 2006. An introduction to current trends and benefits of mobile wireless technology use in higher education. AACE J., 14: 77-100. http://clifmims.com/site/documents/MobileWireles s-HigherEd.pdf

MCMC, 2008. Communications and multimedia selected facts and figures-Q4 2007 annual survey on hand phone users. Cyberjaya, Selangor Darul Ehsan, Malaysia.

Meng, Z., J. Chu and L. Zhang, 2004. Collaborative learning system based on wireless mobile equipments. Elec. Comput. Engineer., 1: 481-484. DOI: 10.1109/CCECE.2004.1345062

Mirski, P.J. and D. Abfalter, 2004. Knowledge enhancement on site-guests' attitudes towards mlearning. Proceeding of the Information and communication technologies in tourism 2004, 11th ENTER International Conference in Cairo, (ICC’04), Cairo, Egypt, pp: 592-600.

Muthaiyah, S., 2004. Key success factors of 3rd generation mobile network services for mcommerce in Malaysia. Am. J. Applied Sci., 1: 261-265. DOI: 10.3844/ajassp.2004.261.265

Nasiri, A. and G. Deng, 2009. Environmental factors influence on mobile learning business. Am. J. Applied Sci., 6: 1225-1234. DOI: 10.3844/ajassp.2009.1225.1234
Prensky, M., 2005. What Can You Learn from a Cell Phone? Almost Anything! Innovation: Journal of Online $\quad$ Education, 1: 1-9. http://www.marcprensky.com/writing/Prenskyhat_Can_You_Learn_From_a_Cell_PhoneFINAL.pdf

Rekkedal, T. and A. Dye, 2007. Mobile distance learning with pdas: development and testing of pedagogical and system solutions supporting mobile distance learners. Int. Rev. Res. Open Distance Learn., $\quad$ 8: 51-74. http://www.aupress.ca/books/120155/ebook/03_M ohamed_Ally_2009-Article3.pdf

Seppala, P., J. Sariola and H. Kynaslahti, 2002. Mobile Learning in Personnel Training of University Teachers. Proceeding of the IEEE International Workshop on Wireless and Mobile Technologies in Education, Aug. 29-30, IEEE Xplore Press, Växjö, Sweden, pp: 136-139.

Sharples, M., D. Corlett and O. Westmancott, 2002. The design and implementation of a mobile learning resource. Personal Ubiquitous Comput., 6; 220-234. DOI: 10.1007/s007790200021

Walton, G., S. Childs and E. Blenkinsopp, 2005. Using mobile technologies to give health students access to learning resources in the UK community setting. Health Inform. Librar. J., 22: 51-65. DOI: 10.1111/j.1470-3327.2005.00615.X

Wentzel, P., R.V. Lammeren, M. Molendijk, S.D. Bruin and A. Wagtendonk, 2005. Using mobile technology to enhance students' educational experiences case study from the EDUCAUSE center for applied research. ECAR Case Study, 2: 1-22. http://igiturarchive.library.uu.nl/DARLIN/2006-1110200247/UUindex.html

Yordanova, K., 2007. Mobile learning and integration of advanced technologies in education. Proceedings of the 2007 International Conference on Computer Systems and Technologies, (ICCST’07), ACM, New York, pp: 21-26. 